Licença CC BY: Artigo distribuído sob os termos Creative Commons, permite uso e distribuição irrestrita em qualquer meio desde que o autor credite a fonte original.

\title{
RESERVAS DE HOTÉIS: ATRIBUTOS IMPORTANTES EM TRANSAÇÕES ON-LINE DOS CLIENTES
}

\author{
HOTEL RESERVATIONS: SIGNIFICANT ATTRIBUTES IN \\ CUSTOMER'S ONLINE TRANSACTIONS
}

MARLUSA DE SEVILHA GOSLING

UNIVERSIDADE FEDERAL DE MINAS GERAIS, BELO HORIZONTE, MINAS GERAIS, BRASIL.

FELIPE WILLIAN TOLEDO FORTES ${ }^{2}$

UNIVERSIDADE FEDERAL DE MINAS GERAIS, BELO HORIZONTE, MINAS GERAIS, BRASIL.

HUMBERTO ELIAS GARCIA LOPES 3

PONTIFÍCIA UNIVERSIDADE CATÓLICA DE MINAS GERAIS, BELO HORIZONTE, MINAS GERAIS, BRASIL.

IURY TEIXEIRA DE SEVILHA GOSLING ${ }^{4}$

UNIVERSIDADE FEDERAL DE LAVRAS, LAVRAS, MINAS GERAIS, BRASIL.

\section{KELLY CRISTINE OLIVEIRA MEIRA ${ }^{5}$ \\ UNIVERSIDADE FEDERAL DE MINAS GERAIS, BELO HORIZONTE, MINAS GERAIS, BRASIL.}

RESUMO: O objetivo desse trabalho é analisar a percepção dos consumidores que utilizam sites de reserva de hotéis e os motivos que geram satisfação com esses sites e levam os consumidores a usá-los e recomendá-los para outras pessoas. Para isso, foi realizada uma pesquisa mista, com uma fase qualitativa exploratória que consistiu de entrevistas semiestruturadas e uma quantitativa por meio de um survey on-line que obteve 306 respondentes. Os dados coletados foram analisados estatisticamente com os softwares SPSS e SmartPLS. Dentre os resultados, destaca-se que a conveniência e a utilidade dos sites são os aspectos que mais impactam na satisfação dos usuários. Quanto à intenção de efetuar uma reserva, constatou-se que a satisfação e o design do site são os fatores que exercem maior influência. Em relação à recomendação, os fatores mais impactantes foram a satisfação e o valor hedônico do site.

1 Professora da Universidade Federal de Minas Gerais, Belo Horizonte, Minas Gerais, Brasil. Pós-doutora em Gestão do Turismo pela Universidade do Algarve, Portugal. E-mail: marlusa@ufmg.br. Orcid: 0000-00027674-2866.

2 Bacharel em Administração pela Universidade Federal de Minas Gerais, Belo Horizonte, Minas Gerais, Brasil. E-mail: felipe.wtf9013@gmail.com. Orcid: 0000-0002-2360-6326.

3 Professor da Pontifícia Universidade Católica de Minas Gerais, Belo Horizonte, Minas Gerais, Brasil. Doutor em Administração pela Universidade Federal de Minas Gerais, Belo Horizonte, Minas Gerais, Brasil. E-mail: heglopes@pucminas.br. Orcid: 0000-0002-6207-2726

4 Doutorando em Administração na Universidade Federal de Lavras, Lavras, Minas Gerais, Brasil. Mestre em Administração pela Universidade Federal de Minas Gerais, Belo Horizonte, Minas Gerais, Brasil. E-mail: iurygosling@gmail.com. Orcid: 0000-0002-6658-9511

5 Mestranda em Ciência Política na Universidade Federal de Minas Gerais, Belo Horizonte, Minas Gerais Brasil. Bacharela em Relações Econômicas Internacionais pela Universidade Federal de Minas Gerais, Belo Horizonte, Minas Gerais Brasil. E-mail: kellycristineomeira@gmail.com. Orcid: 0000-0002-8666-6107 
PALAVRAS-CHAVE: E-commerce. Turismo. Comportamento de consumo.

\begin{abstract}
This paper aims to analyze the perception of consumers who use hotel reservation sites and the reasons that generate satisfaction with these sites and lead them to use them and recommend them to others. For this, a mixed research was conducted, with a qualitative exploratory phase that consisted of semi-structured interviews and a quantitative through an online survey that obtained 306 respondents. The collected data were statistically analyzed using SPSS and SmartPLS software. Among the results, it is noteworthy that the convenience and usefulness of the sites are the aspects that most impact on user satisfaction. As for the intention to make a reservation, it was found that the satisfaction and design of the site are the factors that exert the most influence. Regarding the recommendation, the most impacting factors were the satisfaction and the hedonic value of the site.
\end{abstract}

KEYWORDS: E-commerce. Tourism. Consumer behavior.

\title{
INTRODUÇÃO
}

A indústria do turismo caracteriza-se pela oferta de serviços, que são bens intangíveis. Isso significa que não há como avaliá-los antes de serem consumidos, obrigando seus consumidores a experimentá-los para terem uma posição sobre sua capacidade de satisfazer demandas específicas. Assim, a aquisição desses serviços representa um risco para o consumidor, que precisa pagar por eles independentemente do nível de satisfação a ser obtido nessa transação. Em outras palavras, essa é uma situação em que há assimetria de informação, pois o consumidor não conhece tudo aquilo que precisaria ou desejaria sobre o serviço que será adquirido.

Por sua vez, essa assimetria de informação implica risco de perda para o consumidor, implicando incerteza sobre a satisfação das suas demandas. Sendo ele racional (Mas-Colell, Whinston \& Green, 2010), seu comportamento esperado será o de mitigar tal incerteza e risco, agindo sobre seu fato gerador, ou seja, da assimetria de informação. Para isso, esse consumidor buscará informações anteriores à compra (Barrozo, 2013).

No caso de consumidores do setor de turismo, a internet emerge como uma das alternativas para se obter informações, reduzindo a incerteza e o risco. Isso ocorre por causa da ampla disponibilidade de informações e da sua distribuição direta aos clientes finais. Nota-se que a aquisição de serviços pela internet é uma prática que vem ganhando cada vez mais adeptos, sendo responsável hoje pelo faturamento de grande parte das empresas (Kovacs \& Farias, 2004).

Com a ampla disponibilidade de informações a baixo custo, trazida pela internet, e com a grande concorrência na área do turismo, torna-se primordial entender o comportamento do consumidor. A indústria do turismo é um mercado importante e conectado a outros segmentos, demandando que se aprimorem e se desenvolvam novos produtos e serviços com clara visão do que os consumidores efetivamente procuram. Isso contribui para se entender todo o processo de compra e as necessidades individuais de cada consumidor (Fratu, 2011). 
O objetivo desse trabalho é analisar a percepção dos consumidores que utilizam sites de reserva de hotéis e os motivos que geram satisfação com esses sites e os levam a usá-los e recomendá-los para outras pessoas. Assim, poder-se-á entender quais fatores são mais importantes para os consumidores na qualidade de um website que permite que as empresas que oferecem esses serviços possam desenvolver estratégias e obter melhores resultados. O design do site, a praticidade de uso, a segurança nas transações, a comodidade e a dimensão hedônica são aspectos que contribuem na capacidade do site de persuadir o consumidor a adquirir os serviços ofertados (Molina, Jamilena \& García, 2014; Mirabent, Machuca \& Marimon, 2015).

Portanto, essa pesquisa será desenvolvida com o objetivo de se responder à seguinte pergunta: "Quais atributos dos sites de reserva são mais importantes na intenção de reserva de hotéis, na satisfação e na recomendação dos sites para outros consumidores?"

\section{REFERENCIAL TEÓRICO}

\section{Comércio Eletrônico no Turismo}

O comércio eletrônico no turismo surgiu da combinação da indústria turística com a informação tecnológica moderna e permite aos turistas acessarem informações úteis, fazerem perguntas, procurar por serviços relacionados à viagem e realizar reservas e pagamentos. Essencialmente, o comércio eletrônico de turismo proporciona a compra de passagens de avião, reserva de hotéis, aluguéis de carros e serviços de informação de uma maneira muito mais rápida (Peng \& Lai, 2014). A internet e o comércio eletrônico geraram diversas oportunidades para o turismo, especialmente para o setor hoteleiro. Com a constante redução do custo de se acessar a internet e com a ampliação de sua velocidade, cada vez mais pessoas têm utilizado esse meio para buscar e compartilhar informações. No caso do turismo, esse fator motiva o usuário a utilizá-la cada vez mais, uma vez que oferece importantes oportunidades para todo o planejamento turístico (Carrilho \& Vellani, 2011).

Logo, a web é, atualmente, uma ferramenta importante para o turismo e para as empresas que atuam no setor. O e-commerce no turismo favorece uma maior integração com o consumidor a menores custos. Especificamente nesse setor, o comércio eletrônico possibilita economia, redução de custos da viagem e sensação de liberdade ao consumidor, que pode planejar e se responsabilizar por todas as regras e opções de serviços fornecidos pelos sites (Eltz \& Bridi, 2016).

\section{SATISFAÇÃO}

Para Frederico et al. (2014), a satisfação é definida como o resultado da avaliação da diferença percebida entre as expectativas e as experiências com o 
consumo. Em um contexto de sites de e-commerce, a satisfação do consumidor depende diretamente da capacidade que o website tem de atrair clientes e fazê-los se sentirem em um ambiente confiável e seguro (Oliveira, 2013).

A confiança é fundamentada em uma expectativa de que o prometido, pelo parceiro envolvido na troca, será concretizado (Camargo et al., 2018). Outrossim, é associada positivamente com a satisfação (Oneto et al., 2015; Wu \& Cheng, 2018) e com a percepção de valor (Ladeira et al., 2014).

Ladhari e Michaud (2015) destacam que a confiança ajuda a reduzir a incerteza, a ansiedade e a vulnerabilidade relacionadas às transações on-line, o que, consequentemente, resultará numa maior satisfação dos consumidores. Por fim, Fang et al. (2014) esclarecem que a justificativa para a influência da confiança na satisfação decorre do fato de que a confiança implica em crenças nos resultados positivos das ações das empresas, o que poderia levar a satisfação do consumidor no relacionamento com uma empresa. Com base na revisão de literatura exposta, este estudo propõe a seguinte hipótese:

H1: A confiança influencia positivamente a satisfação.

\section{COMPORTAMENTO DO CONSUMIDOR}

Segundo Peighambari et al. (2016), o comportamento do consumidor sempre foi uma área de interesse para pesquisadores de ciências sociais. A literatura desse campo de estudo é diversa e sofre alterações de acordo as mudanças na sociedade, na economia e na tecnologia. No comportamento do consumidor, estudam-se os compradores e os processos de troca envolvidos na aquisição, no consumo e na disposição de mercadorias, serviços, experiências e ideias (Mowen \& Minor, 2003). Blackwell, Miniard e Engel (2005) apresentam o comportamento do consumidor como aquele que compreende as atividades diretamente envolvidas na obtenção, no consumo e no descarte de produtos e serviços, incluindo o processo de decisão que precede e segue estas ações.

\section{CONSUMIDOR ELETRÔNICO}

Estudos atuais acerca do comportamento do consumidor estão relacionados ao comportamento do cliente no ambiente on-line. O aumento rápido do número de pessoas que escolheu a internet como meio de compras aumentou consideravelmente as vendas virtuais. Pesquisas na área demonstram que a adoção de um website por um cliente está relacionada à utilidade que o mesmo percebe no site e na facilidade de uso. Os consumidores on-line tendem a preferir sites com uma interface bem desenvolvida, de fácil acesso, seguros e que garantam a redução de esforços na compra, ou seja, maior conveniência (Hwang \& Jeong, 2016).

Cummins et al. (2014) afirmam que uma das maiores mudanças referentes ao uso da internet pelas pessoas é que elas deixaram de ser meras consumidoras 
de informação para se tornarem, também, fornecedoras de conteúdo por meio de avaliações, recomendações, opiniões, instruções, fatos e experiências.

Assim, conhecer o comportamento do consumidor que usa a internet para realizar suas compras é importante para indicar tendências e oportunidades de melhorias para as organizações que atuam na área. Além disso, com o aumento de consumidores efetuando compras de bens e serviços online, há uma crescente exigência em relação às empresas no meio eletrônico. A falta de tempo e o estilo de vida também surgem como fatores decisivos para os consumidores realizarem compras através de lojas virtuais, uma vez que estas proporcionam expressivo ganho de tempo em relação ao comércio tradicional (Coelho, Oliveira \& Alméri, 2013).

Geraldo e Mainardes (2017) constatam que, apesar de esperado, a confiança e conveniência não possuem conexão direta com a intenção de compra no mercado online. Os autores justificam este fato ao argumentar que o consumidor virtual considera a confiança e conveniência como essencial, e, portanto, caso não as perceba, pode acarretar em uma não intenção de compra. Posto isto, a seguinte hipótese é apresentada:

H2: A conveniência influencia positivamente a satisfação.

\section{CONSUMIDOR DE TURISMO}

O processo de decisão relacionado à viagem acontece em cinco etapas: o sentimento da necessidade de viajar, a busca por informações, a formação de possibilidade que satisfaçam às necessidades, a compra dos produtos turísticos e, por fim, o sentimento após a avaliação da experiência. As três primeiras etapas fazem parte da viagem pré-imaginária, pois acontecem antes da presença física do turista no local. A quarta etapa é a própria viagem, enquanto a quinta etapa consiste na análise e avaliação do turista sobre sua experiência (Niemczyk, 2014). No que se refere à busca de informações, a internet tem sido uma importante aliada dos consumidores de turismo. Silva e Filho (2014) apontam que cada vez mais os consumidores estão lendo e compartilhando comentários relacionados a viagens na internet que são publicados por viajantes, ao invés de consultarem informações geradas pelos próprios prestadores de serviços turísticos. Assim, os comentários de viagem na internet habilitam os viajantes a tomarem suas próprias decisões sobre o consumo dos serviços e produtos a serem adquiridos. Assim, quanto mais positiva a experiência do consumidor no site, maior é a sua satisfação e confiança em relação ao mesmo (Veludo-de-Oliveira \& Huertas, 2018).

Além disso, a dimensão hedônica também tem demonstrado ser bastante relevante no setor. Uma vez que, o dispêndio hedônico refere-se aos aspectos multissensoriais, emotivos e de fantasia do consumo do produto ou serviço (Leitinho \& Farias, 2018), os consumidores do setor de turismo não estão procurando apenas uma compra excelente e prazerosa de um pacote turístico, mas também buscam uma experiência prazerosa enquanto compram esses serviços (Mirabent, 
Machuca \& Marimon, 2015). Desta forma, propõe-se as hipóteses a seguir:

H3: O valor hedônico influencia positivamente a satisfação.

H4: A experiência com serviços influencia positivamente a satisfação.

\section{FATORES DE QUALIDADE DE SITES}

Parasuraman, Zeithaml e Malhotra (2005) desenvolveram a escala E-SQUAL com o intuito de mensurar a performance de qualidade dos websites. Segundo eles, a qualidade de um website pode ser descrita como a medida em que um website facilita, de forma eficiente e eficaz, as compras e a entrega de produtos e serviços.

Boshoff (2007) submeteu a escala E-S-QUAL a uma avaliação psicométrica. Ele utilizou os mesmos atributos, entretanto, os rearranjou, de maneira a criar três novas dimensões: entrega, velocidade e confiabilidade. Dessa maneira, a pesquisa de Boshoff (2007) utilizou seis dimensões (eficiência, entrega, privacidade, velocidade, disponibilidade do sistema e confiabilidade). Os resultados da pesquisa do autor mostraram que a escala é efetiva em capturar a essência da qualidade do serviço eletrônico, mas que os dados obtidos por meio da E-S-QUAL devem passar por análises mais subjetivas antes que sejam tiradas quaisquer conclusões.

Voltados especificamente para a qualidade de websites de turismo, Chung et al. (2015) combinaram os modelos de DeLone e McLean $(1992,2003)$ com o modelo de Bhattacherjee (2001). Ao combinar esses modelos, os autores construíram um modelo mais integrado de processo de decisão do turista para medir a relação entre a qualidade de um website e os potenciais valores dos turistas como crenças, atitudes, comportamento e intenção de visitar um destino turístico. Para isso, o modelo dos autores verifica o impacto da qualidade do website na utilidade e satisfação que os usuários percebem no mesmo. Além disso, também é analisada a influência da utilidade do site e da satisfação na intenção das pessoas em continuarem o usando. Os resultados da pesquisa mostraram que somente quando os consumidores percebem a utilidade de um site e se sintam satisfeitos eles irão usá-lo continuamente.

Lee e Lin (2005) sugerem que a qualidade do site percebida pelos consumidores influencia positivamente na satisfação dos mesmos e, adicionalmente, Oneto et al. (2015) verificaram que há uma relação direta e positiva entre a utilidade percebida e a satisfação.

Por fim, os atributos do design de um site (dimensão gráfica, layout, acessibilidade, conteúdo, entre outros) são capazes de amplificar as percepções de confiança (Oneto et al., 2015). Assim, os resultados da pesquisa de Dedeke (2016) indicaram que o design do site influencia a qualidade percebida e as intenções de dispêndio virtual. 

propostas:

Com base na revisão de literatura acima, as seguintes hipóteses são

H5: O design influencia positivamente a satisfação.

H6: A utilidade do site influencia positivamente a satisfação.

Para Faizan (2016), a qualidade de websites vem ganhando atenção devido ao seu papel fundamental no desenvolvimento da intenção de compra dos consumidores. O autor ainda afirma que a qualidade de um website envolve várias dimensões, como a qualidade da informação, a qualidade do sistema, a facilidade de uso e o design do site. Além disso, a privacidade e a segurança também são citadas como fatores importantes para evitar incertezas do consumidor em transações online.

A segurança relaciona-se com a apreensão que uma terceira parte tenha acesso à um dado crítico a respeito do comprador online, por exemplo obtenção de dados pessoais ou do cartão de crédito (Oneto et al., 2015). Desta forma, de acordo com os autores, a satisfação possui relação direta e positiva com a segurança. Assim, declara-se a seguinte hipótese:

H7: A segurança influencia positivamente a satisfação.

\section{INTENÇÃO DE RESERVA}

A intenção de compra é definida como um plano ou intenção consciente que o consumidor tem em realizar um esforço para comprar um produto. A intenção de reserva é similar à intenção de compra. Para o presente estudo, será utilizada a definição de Yenn Wei et al. (2014) que descrevem a intenção de reserva como a intenção do consumidor em reservar um quarto em um hotel.

O entretenimento - ou comportamento hedônico - também influencia as compras online. Se o consumidor consegue experimentar sentimentos como alegria e satisfação, irá, consequentemente, considerar uma compra online. A segurança e privacidade também afetam a decisão do consumidor em efetuar transações no ambiente virtual (Vilar, 2013). Assim como Cho e Kim (2012), Vilar (2013) também destaca que as características do website, tais como seu design e sua imagem também influenciam a intenção do consumidor em comprar através da internet. Essas características são consideradas uma espécie de fator motivacional que pode criar um sentimento positivo ou negativo em relação a um website. Logo, é possível inferir que se um site possui aspectos de boa qualidade e orienta o consumidor com clareza a realizar transações, ele atrairá o consumidor a realizar compras novamente (Vilar, 2013). Deste modo, de acordo com Oneto et al. (2015), a confiança e satisfação são predecessoras da intenção de compra. Considerando a literatura apresentada, a seguinte hipótese é declarada:

H8: A satisfação influencia positivamente a intenção de reserva. 


\section{RECOMENDAÇÃO}

A recomendação está relacionada ao boca-a-boca positivo sobre serviços e produtos. No contexto turístico, a influência interpessoal e a comunicação boca-a-boca são as principais fontes de informação do processo decisório de um consumidor. A internet propiciou novas plataformas de comunicação que deram poder de voz aos consumidores, permitindo o compartilhamento de informações entre os mesmos (Litvin et al., 2008).

Para Frederico et al. (2014), a recomendação espontânea é descrita como a troca de informações e divulgação de determinada marca, serviço ou produto através de meios interpessoais espontâneos. Litvin et al. (2008) ressaltam, ainda, que o boca-a-boca pode ser tanto positivo quanto negativo.

Segundo Shoemaker e Lewis (1999), uma das vantagens da recomendação para as organizações que atuam na área do turismo é o fato de que os consumidores promovem o boca-a-boca positivo de forma gratuita. Além disso, a recomendação em turismo também é relacionada à satisfação, de maneira que turistas mais satisfeitos costumam recomendar ou emitir comentários favoráveis (Coelho, 2013).

Por fim, é importante frisar que a recomendação possui um caráter principalmente positivo e tem maior credibilidade junto aos clientes do que ações convencionais de marketing além de ter um potencial de se difundir com menor esforço de marketing das empresas (Villanueva, Yoo \& Hanssens, 2008). Assim, é proposta a última hipótese deste estudo:

H9: A satisfação influencia positivamente a recomendação.

\section{METODOLOGIA}

O método de pesquisa do presente estudo envolve uma abordagem mista, uma vez que houve uma fase qualitativa e outra quantitativa. A fase qualitativa foi importante para melhor compreensão do problema e das variáveis a serem estudadas, além de colaborar para a parte quantitativa.

$\mathrm{Na}$ fase qualitativa foram realizadas entrevistas com pessoas que utilizam sites de reserva de hotéis frequentemente, visando a construção do questionário e a descoberta de variáveis a serem estudadas. Já na fase quantitativa foi utilizado um survey online por meio da plataforma gratuita Google Forms, que possibilita respostas rápidas com um alcance expressivo e a facilidade de análise dos dados obtidos. Na fase quantitativa foram testadas as hipóteses apresentadas anteriormente.

\section{FASE QUALITATIVA}

Na estratégia de pesquisa foi definido que seriam realizadas entrevistas estruturadas com onze pessoas que utilizam sites de reserva de hotéis com certa 
frequência. O objetivo era obter mais informações a respeito da experiência que tiveram, compreender melhor o problema de pesquisa e a descoberta de possíveis variáveis a serem estudadas. Além disso, as entrevistas foram necessárias para auxiliar na construção do questionário. Assim, foram realizadas onze entrevistas, utilizando-se de um roteiro breve, com quatro perguntas. A seguir, as perguntas do questionário:

Quadro 1 - Perguntas do Questionário Qualitativo

\begin{tabular}{|l||}
\hline \multicolumn{1}{|c||}{ Pergunta } \\
\hline - Por qual motivo você utiliza sites de reserva para escolher um hotel? \\
\hline - Que vantagens você vê em reservar por sites de reserva? \\
\hline - O que te levaria a não utilizar mais esses sites? \\
\hline - Você recomendaria a outras pessoas que reservassem um hotel por \\
meio desses sites? Se sim, por quê?
\end{tabular}

Fonte: Elaborado pelo autor, 2016.

\section{FASE QUANTITATIVA}

A coleta dos dados ocorreu por meio de um survey online utilizando a plataforma Google Forms. O questionário ficou disponível para respostas entre os dias 27 de agosto e 13 de setembro de 2016. A conclusão da pesquisa pelos respondentes durou em torno de cinco minutos. O questionário obteve 517 respostas das quais 211 foram desconsideradas por não se adequarem aos propósitos da pesquisa. Para promover o questionário foi utilizado a técnica de bola de neve, na qual as pessoas respondem e colaboram para a divulgação do mesmo. Primeiramente, a pesquisa foi anuncia da emredes sociais e posteriormente foi compartilhada pelos respondentes. Para tornar a participação mais atrativa, foi sorteado um vale-presente no valor de $R \$ 100,00$.

Foi estabelecido como meta dez vezes o número de variáveis presentes no questionário como forma de determinar a amostragem mínima. Portanto, como havia 31 variáveis, o número mínimo de participantes foi de 310 pessoas, valor que foi superado.

No início da pesquisa os participantes eram apresentados à perguntafiltro visando identificar se os respondentes já haviam utilizado algum site de reserva de hotel. Quando a resposta era negativa, a pesquisa era encerrada e uma mensagem apresentada aos participantes explicando que essa era uma condição para o prosseguimento. Caso a resposta fosse afirmativa, o questionário era iniciado, passando por 31 perguntas relacionadas aos atributos dos sites de reserva de hotéis e a três perguntas demográficas (sexo, idade e grau de escolaridade), além de informarem em qual site têm mais costume de realizar a reserva de hotéis. Foi perguntado, ainda, para qual finalidade a 
pessoa utiliza os sites de reserva (lazer ou trabalho). Por último, foi perguntado se a pessoa tinha interesse em participar do sorteio do vale-presente e aqueles que manifestassem interesse eram encaminhados para outra página, tendo que informar o nome, telefone e e-mail.

O questionário foi montado tendo como base as pesquisas de Chung et al. (2015) e Boshoff (2007), além de dados obtidos da pesquisa qualitativa. Assim, foram criadas sete dimensões (utilidade, confiança, experiência com os serviços, valor hedônico, design, segurança e conveniência). O modo como os atributos dos trabalhos de Chung et al. (2015), Boshoff (2007) e da pesquisa qualitativa foram rearranjados é apresentado no Quadro 2:

Quadro 2 - Dimensões, indicadores e referências

\begin{tabular}{|c|c|c|}
\hline \multicolumn{3}{|c|}{ Os sites de reserva de hotéis... } \\
\hline Cod. & Indicador & Referência \\
\hline UTI1 & $\begin{array}{l}\text { Auxiliam-me a encontrar o que estou } \\
\text { precisando. }\end{array}$ & (Boshoff, 2007) \\
\hline UTI2 & $\begin{array}{l}\text { Fornecem serviços bem distribuídos em termos } \\
\text { de quantidade e qualidade. }\end{array}$ & $\begin{array}{l}\text { (Chung et al., } \\
\text { 2015) }\end{array}$ \\
\hline UTI3 & Fornecem serviços muito úteis para mim. & $\begin{array}{l}\text { (Chung et al., } \\
2015 \text { ) }\end{array}$ \\
\hline CONFI & $\begin{array}{l}\text { Apresentam ofertas verdadeiras de seus } \\
\text { serviços. }\end{array}$ & (Boshoff, 2007) \\
\hline CONF2 & $\begin{array}{l}\text { Fornecem informações verdadeiras sobre os } \\
\text { hotéis e demais serviços ofertados. }\end{array}$ & $\begin{array}{l}\text { Pesquisa } \\
\text { qualitativa }\end{array}$ \\
\hline CONF3 & $\begin{array}{l}\text { Apresentam comentários, fotos e avaliações } \\
\text { verdadeiras dos seus serviços. }\end{array}$ & $\begin{array}{l}\text { Pesquisa } \\
\text { qualitativa }\end{array}$ \\
\hline EXP1 & $\begin{array}{l}\text { Oferecem serviços adequados (hospedagem, } \\
\text { aluguel de carros, compra passagens, compra } \\
\text { passeios). }\end{array}$ & $\begin{array}{l}\text { Pesquisa } \\
\text { qualitativa }\end{array}$ \\
\hline EXP2 & $\begin{array}{l}\text { Melhoram bastante a experiência do } \\
\text { usuário por meio de seus diversos serviços } \\
\text { (hospedagem, aluguel de carros, compra } \\
\text { passagens, compra passeios). }\end{array}$ & $\begin{array}{l}\text { Pesquisa } \\
\text { qualitativa }\end{array}$ \\
\hline EXP3 & $\begin{array}{l}\text { Permitem que eu encontre comentários e } \\
\text { avaliações adequadas. }\end{array}$ & $\begin{array}{l}\text { (Chung et al., } \\
2015 \text { ) }\end{array}$ \\
\hline VAL1 & Possuem comentários divertidos de se ler. & $\begin{array}{l}\text { (Chung et al., } \\
2015 \text { ) }\end{array}$ \\
\hline VAL2 & Têm bastante coisa para se ler. & $\begin{array}{l}\text { (Chung et al., } \\
2015 \text { ) }\end{array}$ \\
\hline VAL3 & Não são entediantes. & $\begin{array}{l}\text { (Chung et al., } \\
2015 \text { ) }\end{array}$ \\
\hline
\end{tabular}




\begin{tabular}{|c|c|c|}
\hline VAL4 & São prazerosos de se usar. & $\begin{array}{l}\text { (Chung et al., } \\
2015 \text { ) }\end{array}$ \\
\hline DES 1 & Apresentam um aspecto visual prático. & $\begin{array}{l}\text { (Chung et al., } \\
2015 \text { ) }\end{array}$ \\
\hline DES2 & Apresentam um design de fácil entendimento. & $\begin{array}{l}\text { (Chung et al., } \\
2015 \text { ) }\end{array}$ \\
\hline DES3 & São fáceis de encontrar o que eu preciso. & $\begin{array}{l}\text { (Chung et al., } \\
2015 \text { ) }\end{array}$ \\
\hline SEG 1 & $\begin{array}{l}\text { Mantêm sigilo sobre as informações pessoais } \\
\text { dos clientes. }\end{array}$ & (Boshoff, 2007) \\
\hline SEG2 & $\begin{array}{l}\text { Não compartilham com outros sites } \\
\text { informações pessoais dos clientes. }\end{array}$ & (Boshoff, 2007) \\
\hline SEG3 & Apresentam formas de pagamento seguras. & $\begin{array}{l}\text { Pesquisa } \\
\text { qualitativa }\end{array}$ \\
\hline CONV1 & Proporcionam economia de tempo. & $\begin{array}{l}\text { Pesquisa } \\
\text { qualitativa }\end{array}$ \\
\hline CONV2 & $\begin{array}{l}\text { Possibilitam a comparação entre tipos } \\
\text { de hospedagem, preços e condições de } \\
\text { pagamento. }\end{array}$ & $\begin{array}{l}\text { Pesquisa } \\
\text { qualitativa }\end{array}$ \\
\hline CONV3 & $\begin{array}{l}\text { São bastante práticos para se efetuar a reserva } \\
\text { de um hotel. }\end{array}$ & $\begin{array}{l}\text { Pesquisa } \\
\text { qualitativa }\end{array}$ \\
\hline CONV4 & $\begin{array}{l}\text { Proporcionam cancelar uma reserva de forma } \\
\text { fácil e rápida. }\end{array}$ & $\begin{array}{l}\text { Pesquisa } \\
\text { qualitativa }\end{array}$ \\
\hline CONV5 & $\begin{array}{l}\text { Possuem vários filtros que me permitem refinar } \\
\text { a busca de acordo com meu perfil. }\end{array}$ & $\begin{array}{l}\text { Pesquisa } \\
\text { qualitativa }\end{array}$ \\
\hline SATI & $\begin{array}{l}\text { Em geral, qual seu grau de satisfação com os } \\
\text { sites de reserva? }\end{array}$ & $\begin{array}{l}\text { Elaborado para a } \\
\text { pesquisa }\end{array}$ \\
\hline INTI & $\begin{array}{l}\text { Sites de reserva são sempre a minha primeira } \\
\text { opção quando preciso de hospedagem. }\end{array}$ & $\begin{array}{l}\text { (Yenn Wei et al., } \\
2014 \text { ) }\end{array}$ \\
\hline INT2 & $\begin{array}{l}\text { É provável que eu utilize um site de reserva na } \\
\text { próxima vez que for reservar um hotel. }\end{array}$ & $\begin{array}{l}\text { (Yenn Wei et al., } \\
\text { 2014) }\end{array}$ \\
\hline INT3 & $\begin{array}{l}\text { Eu pretendo continuar usando sites para } \\
\text { reservar um hotel. }\end{array}$ & $\begin{array}{l}\text { (Yenn Wei et al., } \\
\text { 2014) }\end{array}$ \\
\hline REC 1 & $\begin{array}{l}\text { Eu recomendo o uso de sites de reserva para } \\
\text { outras pessoas. }\end{array}$ & (Coelho, 2013) \\
\hline REC2 & $\begin{array}{l}\text { Eu digo coisas positivas a outras pessoas sobre } \\
\text { utilizar sites de reserva de hotéis. }\end{array}$ & (Coelho, 2013) \\
\hline REC3 & $\begin{array}{l}\text { Eu pretendo compartilhar informações } \\
\text { (fotos, comentários, avaliações) sobre minha } \\
\text { experiência com sites de reserva. }\end{array}$ & (Coelho, 2013) \\
\hline
\end{tabular}

Fonte: Elaborado pelos autores, 2016.

Esses indicadores foram medidos por meio de escalas do tipo Likert de 
onze categorias. Essa estratégia é recomendada em estudos que utilizam técnicas paramétricas de análise dos dados, como é o caso do PLS. Isso ocorre porque a escala com sete ou mais categorias permite uma dispersão suficiente nos dados para que $O$ indicador não produza os vieses que poderiam ocorrer em escalas com menos categorias (Nunnally \& Berstein, 1994).

\section{ANÁLISE E DISCUSSÃO DE RESULTADOS}

Os resultados apresentados nessa etapa foram divididos em duas partes principais. Primeiramente, a etapa qualitativa com os usuários de sites de reserva buscou obter mais informações a respeito da experiência que tiveram, uma melhor compreensão do problema de pesquisa e a descoberta de possíveis variáveis a serem estudadas. A segunda parte, de análise quantitativa dos dados, envolveu testes estatísticos e a descrição dos resultados encontrados no modelo de pesquisa que foram analisados através do software SPSS (Statistical Package for the Social Sciences) e a análise do modelo de mensuração e estrutural que foi analisado com o suporte do software Smart PLS.

\section{ANÁLISE QUALITATIVA}

Em relação aos motivos que levam os entrevistados a utilizarem sites de reserva para escolher um hotel, praticamente todos citaram a praticidade, comodidade, a possibilidade de ver as avaliações de hóspedes e recomendações dos mesmos. Quanto às vantagens que os entrevistados veem em fazer reserva por meio desses sites, estão a praticidade na forma de pagamento assim como a segurança de poder viajar mais tranquilo e ter várias formas de pagar pela reserva de maneira segura. Todos esses fatores foram levados em consideração para se formular o construto Conveniência, especificamente os itens CONVI, CONV2 e CONV3. Os demais itens desse construto também foram formulados a partir das entrevistas, uma vez que alguns entrevistados citaram a facilidade de cancelar as reservas e a possibilidade de filtrar suas pesquisas de acordo com seus interesses como motivos que os levam a utilizar os sites de reserva. Assim, chegou-se aos indicadores CONV4 e CONV5.

Quanto aos motivos que levariam os entrevistados a não utilizarem mais esses sites, foram citados fatores relacionados principalmente à segurança e confiança. Assim, a partir dessas respostas, chegou-se a itens dos construtos Confiança e Segurança, especificamente os indicadores CONF2 (Os sites de reserva fornecem informações verdadeiras sobre os hotéis e demais serviços ofertados), CONF3 (Os sites de reserva apresentam comentários, fotos e avaliações verdadeiras dos seus serviços) e SEG3 (Os sites de reserva apresentam formas de pagamento seguras). Para se chegar aos indicadores EXP1 e EXP2 levou-se em consideração a resposta de uma das entrevistadas quando perguntada sobre quais motivos a leva a utilizar os sites de reserva. Assim, identificou-se pela fala dos entrevistados que eles utilizam os sites de reserva buscando praticidade e comodidade para suas viagens. Além disso, grande parte ressaltou que a segurança nas formas de pagamento e confiança no site, nas avaliações, fotos 
e recomendações presentes nos mesmos são primordiais para que continuem a usar esses serviços. Portanto, a visão dos entrevistados serviu para uma melhor compreensão do problema e na descoberta de possíveis variáveis, além de reforçar alguns dos itens do questionário que haviam sido extraídos da literatura usada como referência, uma vez que as respostas dos usuários foram ao encontro do que consta na literatura sobre sites de reserva de hotéis.

\section{ANÁLISE QUANTITATIVA}

\section{Caracterização da Amostra}

A amostra total obtida na pesquisa foi de 517 respondentes, dos quais 211 foram desconsiderados por não se enquadrarem no perfil de consumidor procurado para esta pesquisa nos quais também se incluem 7 casos de respostas duplicadas, 7 outliers univariados e 4 outliers multivariados. Dessa maneira, chegou-se ao número final de 306 respondentes válidos.

A amostra é composta na maioria por mulheres $(64,7 \%)$ enquanto os homens representam $35,3 \%$ da mesma. Como é possível notar, houve uma diferença significativa a favor das mulheres, fato que não é passível de justificativa, já que a prospecção dos respondentes foi feita de maneira aleatória, além de não ser esse um dos objetivos do estudo.

Em relação à faixa etária, a maior parte dos participantes tem entre $18 \mathrm{e}$ 24 anos $(62,4 \%)$ seguido pelo grupo de pessoas entre 25 e 35 anos $(28,1 \%)$. Os dois grupos somados representam $90,5 \%$ do total, o que demonstra predominância de pessoas jovens entre os respondentes. É importante lembrar que o principal método de obtenção de respondentes para a pesquisa foi feito através de redes sociais, o que explica, em parte, o número expressivo de jovens entre os participantes da pesquisa, já que eles são os principais usuários dessas redes.

Em termos de escolaridade, a maior parte dos entrevistados tem ensino superior incompleto $(57,1 \%)$, seguidos de pessoas que já completaram o ensino superior (34\%). Uma menor parte da amostra tem ensino médio incompleto e ensino fundamental completo $(0,7 \%$ cada, respectivamente). Pessoas com ensino médio completo totalizaram $7,5 \%$ da amostra. Nenhum entrevistado afirmou possuir ensino fundamental incompleto. Em relação aos sites que os participantes têm o hábito de acessar para realizar suas reservas, os resultados demonstraram que o preferido é o Booking (63,9\% dos respondentes utilizam o site para efetuar suas reservas). Os sites Decolar.com (58\%) e Trivago (41,4\%), também foram bastante citados entre os preferidos pelos usuários desse serviço. Vale ressaltar que nesta pergunta, os respondentes poderiam escolher mais de um site que costumam utilizar para fazer reservas. Por último, foi explorado para qual finalidade os participantes da pesquisa utilizam os sites de reserva com mais frequência. A maioria absoluta (93,5\%) afirmou que utiliza os sites de reserva para lazer, enquanto apenas 6,5\% usa para trabalho. 
4.2.2 Análise de Outliers Uni e Multivariados, Normalidade, Linearidade e Estatísticas Descritivas

A análise da normalidade dos dados é feita com base na curva de distribuição normal ao se comparar os dados de uma determinada amostra com uma distribuição normal com a mesma média e mesmo desvio padrão (Hair et al., 2014). A normalidade univariada é um dos dois critérios para que haja normalidade multivariada. Isto é, na ausência da normalidade univariada, nem é necessário testar a combinação das variáveis, pois certamente não haverá normalidade multivariada.

A avaliação da normalidade dos dados contribui para a determinação dos testes estatísticos a serem efetuados na amostra. Em geral, são utilizados os testes de normalidade de Kolmogorov-Smirnov para amostras superiores a 50 (Hair et al., 2005). Desse modo, a análise de normalidade da amostra foi baseada no teste de Kolmogorov-Smirnov com suporte do SPSS. Os dados não foram normais univariado de acordo com o teste de Kolmogorov-Smirnov, consequentemente, não existe normalidade multivariada e por isso optou-se por testar o modelo usando o SmartPLS para a aplicação de métodos estatísticos multivariados, uma vez que o PLS é um método estatístico não paramétrico, que não requer que os dados sejam distribuídos com normalidade (Hair et al., 2014).

Assim como a normalidade, a linearidade é uma das suposições implícitas das técnicas estatísticas multivariadas (Hair et al., 2005). Assim, antes de prosseguir com a modelagem de equações estruturais é necessário avaliar a linearidade dos dados das amostras.

Para testar a linearidade, calculou-se a correlação linear par a par, utilizando-se a correlação de Spearman. A escolha deste teste é justificada pelos resultados do teste de normalidade que indicaram ausência de normalidade. Avaliou-se a porcentagem de correlações significativas de cada amostra, as quais indicam a presença de dados lineares. Os outliers são observações atípicas que apresentam uma resposta extrema em uma questão específica ou uma combinação única de respostas, significativamente diferente dos padrões observados pela maioria dos entrevistados (Hair et al., 2005; 2014).

Conforme sugestão de Hair et al. (2005), a análise de outliers univariada pode utilizar escores do módulo em relação ao desvio padrão de 2,5, para amostras pequenas, já a análise de outliers multivariada foi baseada no cálculo da distância de Mahalanobis $\left(\mathrm{D}^{2}\right)$ dividido pelo grau de liberdade, com suporte do SPSS. Na amostra, não foram detectados outliers uni ou multivariados.

Entre todos os indicadores, INT3 apresenta a mais alta média $(8,71)$, além disso, as notas de todos indicadores ficaram acima de 8 e desvios padrões abaixo de 3 , o que demonstra grande possibilidade dos consumidores continuarem utilizando os sites para fazerem suas reservas.

O atributo REC3 (EU pretendo compartilhar informações sobre minha experiência com sites de reserva de hotéis) teve a menor nota média entre todos os indicadores, apenas 5,29. Quanto aos desvios padrões, é possível afirmar 
que houve homogeneidade nas respostas, já que os dois primeiros itens ficaram abaixo de 3, enquanto o terceiro superou apenas levemente a marca de 3. Pelas notas dos indicadores REC1 e REC2 é possível notar forte possibilidade de recomendação e divulgação de informações positivas dos sites, já que a menor nota foi 7,83. Com exceção de REC3, cujo desvio padrão é levemente superior a 3 , os desvios padrões de todos os demais indicadores ficaram abaixo de 3, o que demonstra pouca variabilidade nas respostas.

Tabela 1 - Estatísticas Descritivas

\begin{tabular}{|c|c|c|c|c|c|c|}
\hline & \multicolumn{2}{|l|}{$N$} & \multirow[b]{2}{*}{ Média } & \multirow{2}{*}{$\begin{array}{l}\text { Desvio } \\
\text { Padrão }\end{array}$} & \multirow[b]{2}{*}{ Mínimo } & \multirow[b]{2}{*}{ Máximo } \\
\hline & Válido & Ausente & & & & \\
\hline UTII & 306 & 0 & 8,26 & 1,534 & 3 & 10 \\
\hline UTI2 & 306 & 0 & 7,65 & 1,617 & 2 & 10 \\
\hline UTI3 & 306 & 0 & 8,11 & 1,689 & 2 & 10 \\
\hline CONFI & 306 & 0 & 6,98 & 1,897 & 2 & 10 \\
\hline CONF2 & 306 & 0 & 7,16 & 1,668 & 2 & 10 \\
\hline CONF3 & 306 & 0 & 7,38 & 1,832 & 2 & 10 \\
\hline EXP1 & 306 & 0 & 7,28 & 1,911 & 1 & 10 \\
\hline EXP2 & 306 & 0 & 7,18 & 2,084 & 0 & 10 \\
\hline EXP3 & 306 & 0 & 7,80 & 1,843 & 2 & 10 \\
\hline VAL1 & 306 & 0 & 5,88 & 2,711 & 0 & 10 \\
\hline VAL2 & 306 & 0 & 6,26 & 2,359 & 0 & 10 \\
\hline VAL3 & 306 & 0 & 6,10 & 2,245 & 0 & 10 \\
\hline VAL4 & 306 & 0 & 6,17 & 2,178 & 0 & 10 \\
\hline DES 1 & 306 & 0 & 6,99 & 2,171 & 0 & 10 \\
\hline DES2 & 306 & 0 & 7,14 & 2,082 & 0 & 10 \\
\hline DES3 & 306 & 0 & 7,25 & 1,887 & 0 & 10 \\
\hline SEG 1 & 306 & 0 & 7,17 & 2,317 & 0 & 10 \\
\hline SEG2 & 306 & 0 & 6,17 & 2,776 & 0 & 10 \\
\hline SEG3 & 306 & 0 & 8,11 & 1,795 & 1 & 10 \\
\hline CONVI & 306 & 0 & 8,54 & 1,669 & 3 & 10 \\
\hline CONV2 & 306 & 0 & 8,06 & 2,132 & 0 & 10 \\
\hline CONV3 & 306 & 0 & 8,22 & 1,741 & 2 & 10 \\
\hline CONV4 & 306 & 0 & 6,36 & 2,601 & 0 & 10 \\
\hline CONV5 & 306 & 0 & 8,02 & 1,942 & 1 & 10 \\
\hline SATI & 306 & 0 & 7,83 & 1,515 & 2 & 10 \\
\hline INTI & 306 & 0 & 8,12 & 2,280 & 0 & 10 \\
\hline INT2 & 306 & 0 & 8,70 & 1,791 & 1 & 10 \\
\hline INT3 & 306 & 0 & 8,71 & 1,784 & 2 & 10 \\
\hline
\end{tabular}




\begin{tabular}{|l|l|l|l|l|l|l|} 
REC1 & 306 & 0 & 8,39 & 1,947 & 0 & 10 \\
REC2 & 306 & 0 & 7,83 & 2,131 & 0 & 10 \\
REC3 & 306 & 0 & 5,29 & 3,046 & 0 & 10 \\
\hline
\end{tabular}

Fonte: Elaborado pelos autores, 2016.

\section{MODELO DE MENSURAÇÃO}

O modelo de mensuração foi composto pelas medidas de Confiabilidade (simples e composta), pela Validade Convergente (variância média extraída e cargas externas) e pela Validade Discriminante (cargas cruzadas, Fornell-Larcker e Heterotrait-Monotrait Ratio), e, foi testado com o suporte do software SmartPLS.

Ao testar o modelo no software SmartPLS verificou-se a necessidade da exclusão do indicador REC3 para tornar o modelo mais adequado e confiável.

Figura 1 - Modelo de Mensuração

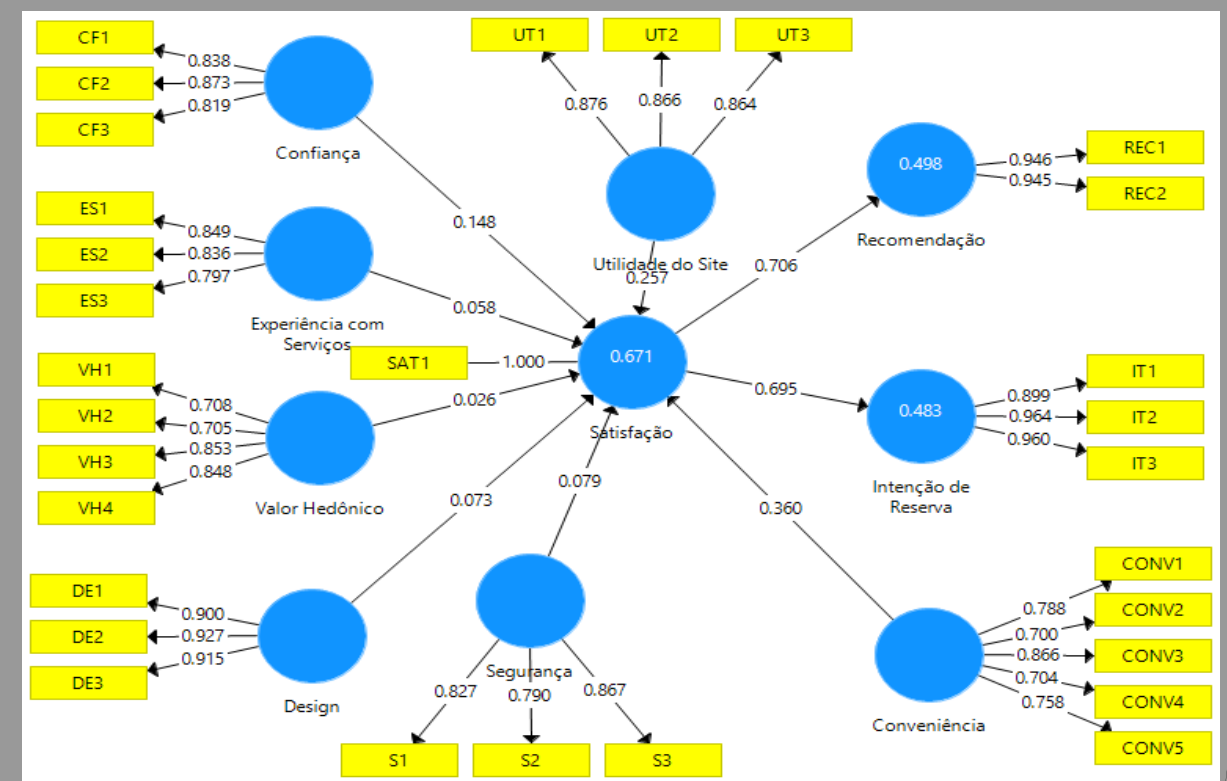

Fonte: Saída do Software SmartPLS

Para se medir quão confiável são as medidas da escala utilizada, estimou-se o coeficiente Alfa de Cronbach de cada construto, que analisa a consistência interna dos mesmos. Ademais, a confiabilidade composta privilegia indicadores conforme sua confiabilidade, proporcionando uma maior composição confiável (Henseler et al., 2009). Os parâmetros para avaliação da confiabilidade composta indicados pelos autores é usualmente interpretado igual aos do Alfa de Cronbach, sendo o limite adequado entre 0,70 e 0,90.

A AVE é a medida para estabelecer a validade convergente no nível 
do construto, um valor de AVE igual ou maior que 0,50 indica que, em média, o construto explica mais da metade da variação dos seus indicadores. A AVE não é indicada para construtos de único item, uma vez que a carga externa do indicador é fixada em 1,00 (Hair et al., 2014).

Tabela 2 - Confiabilidade Simples e Composta

\begin{tabular}{|llll|}
\hline & $\begin{array}{l}\text { Confiabilidade } \\
\text { Simples } \\
\text { Alpha de Cronbach } \\
>\mathbf{0 , 7 0}\end{array}$ & $\begin{array}{l}\text { Confiabilidade } \\
\text { Composta } \\
\text { Confiabilidade } \\
\text { Composta }>\mathbf{0 , 7 0}\end{array}$ & AVE \\
\hline Confiança & 0,797 & 0,881 & 0,712 \\
Conveniência & 0,822 & 0,876 & 0,586 \\
Design & 0,902 & 0,938 & 0,835 \\
Exp. com Serviços & 0,771 & 0,867 & 0,685 \\
Intenção de & 0,936 & 0,959 & 0,887 \\
Reserva & 0,881 & 0,944 & 0,894 \\
Recomendação & 0,000 & 1,000 & 1,000 \\
Satisfação & 0,787 & 0,868 & 0,687 \\
Segurança & 0,838 & 0,902 & 0,755 \\
Utilidade do Site & 0,838 & 0,611 \\
Valor Hedônico & 0,789 & & \\
\hline
\end{tabular}

Fonte: Saída do Software SmartPLS

Outro procedimento sugerido por Hair et al. (2014) é a avaliação das cargas externas. Para Hair et al. (2014), todos os valores devem ser maiores que 0,708 . 
Tabela 3 - Cargas Externas

\section{Cargas Externas $>0,70$}

\begin{tabular}{|c|c|c|c|c|c|c|c|c|c|c|}
\hline \multicolumn{11}{|c|}{ Cargas Externas $>0,70$} \\
\hline & Conf. & Conven. & Design & $\begin{array}{l}\text { Exp. c/ } \\
\text { Serviços }\end{array}$ & $\begin{array}{l}\text { Int. de } \\
\text { Reserva }\end{array}$ & Recomen. & Satisf. & Segur. & $\begin{array}{l}\text { Util. } \\
\text { do } \\
\text { Site }\end{array}$ & $\begin{array}{l}\text { Valor } \\
\text { Hedônico }\end{array}$ \\
\hline CF1 & 0,838 & & & & & & & & & \\
\hline CF2 & 0,873 & & & & & & & & & \\
\hline CF3 & 0,819 & & & & & & & & & \\
\hline CONV1 & & 0,788 & & & & & & & & \\
\hline CONV2 & & 0,700 & & & & & & & & \\
\hline CONV3 & & 0,866 & & & & & & & & \\
\hline CONV4 & & 0,704 & & & & & & & & \\
\hline CONV5 & & 0,758 & & & & & & & & \\
\hline DEl & & & 0,900 & & & & & & & \\
\hline DE2 & & & 0,927 & & & & & & & \\
\hline DE3 & & & 0,915 & & & & & & & \\
\hline ES 1 & & & & 0,849 & & & & & & \\
\hline ES2 & & & & 0,836 & & & & & & \\
\hline ES3 & & & & 0,797 & & & & & & \\
\hline IT1 & & & & & 0,899 & & & & & \\
\hline IT2 & & & & & 0,964 & & & & & \\
\hline IT3 & & & & & 0,960 & & & & & \\
\hline REC 1 & & & & & & 0,946 & & & & \\
\hline REC2 & & & & & & 0,945 & & & & \\
\hline S1 & & & & & & & & 0,827 & & \\
\hline S2 & & & & & & & & 0,790 & & \\
\hline S3 & & & & & & & & 0,867 & & \\
\hline SAT1 & & & & & & & 1,000 & & & \\
\hline UT 1 & & & & & & & & & 0,876 & \\
\hline UT2 & & & & & & & & & 0,866 & \\
\hline UT3 & & & & & & & & & 0,864 & \\
\hline VHI & & & & & & & & & & 0,708 \\
\hline $\mathrm{VH} 2$ & & & & & & & & & & 0,705 \\
\hline VH3 & & & & & & & & & & 0,853 \\
\hline VH4 & & & & & & & & & & 0,848 \\
\hline
\end{tabular}

Fonte: Saída do Software SmartPLS

Um método utilizado para verificar a validade discriminante é avaliar as cargas cruzadas segundo a qual a carga de um indicador sobre o construto associado deve ser maior que todas as cargas desse indicador sobre outros construtos (Hair et al., 2014).

Todos os valores de Cargas Cruzadas da tabela 4 são adequados de acordo com os parâmetros usados. 
Tabela 4 - Cargas Cruzadas

\section{Cargas Cruzadas}

\begin{tabular}{|c|c|c|c|c|c|c|c|c|c|c|}
\hline & Conf. & Conven. & Design & $\begin{array}{l}\text { Exp. c/ } \\
\text { Serviços }\end{array}$ & $\begin{array}{l}\text { Int. de } \\
\text { Reserva }\end{array}$ & Recomen. & Satisf. & Segur. & $\begin{array}{l}\text { Ufil. } \\
\text { do } \\
\text { Site }\end{array}$ & $\begin{array}{l}\text { Valor } \\
\text { Hedôn. }\end{array}$ \\
\hline CF1 & 0,838 & 0,490 & 0,401 & 0,442 & 0,382 & 0,418 & 0,534 & 0,372 & 0,526 & 0,318 \\
\hline CF2 & 0,873 & 0,476 & 0,408 & 0,463 & 0,390 & 0,372 & 0,509 & 0,390 & 0,465 & 0,382 \\
\hline CF3 & 0,819 & 0,476 & 0,439 & 0,579 & 0,416 & 0,419 & 0,535 & 0,388 & 0,513 & 0,419 \\
\hline CONVI & 0,428 & 0,788 & 0,539 & 0,503 & 0,511 & 0,517 & 0,596 & 0,467 & 0,526 & 0,375 \\
\hline CONV2 & 0,368 & 0,700 & 0,452 & 0,453 & 0,371 & 0,419 & 0,429 & 0,346 & 0,401 & 0,324 \\
\hline CONV3 & 0,510 & 0,866 & 0,668 & 0,531 & 0,621 & 0,611 & 0,676 & 0,526 & 0,530 & 0,493 \\
\hline CONV4 & 0,418 & 0,704 & 0,439 & 0,402 & 0,445 & 0,480 & 0,532 & 0,440 & 0,404 & 0,369 \\
\hline CONV5 & 0,444 & 0,758 & 0,581 & 0,479 & 0,459 & 0,529 & 0,600 & 0,370 & 0,489 & 0,472 \\
\hline DE 1 & 0,397 & 0,583 & 0,900 & 0,429 & 0,467 & 0,447 & 0,506 & 0,402 & 0,473 & 0,580 \\
\hline DE2 & 0,444 & 0,645 & 0,927 & 0,458 & 0,510 & 0,469 & 0,576 & 0,392 & 0,479 & 0,489 \\
\hline DE3 & 0,503 & 0,705 & 0,915 & 0,501 & 0,547 & 0,523 & 0,616 & 0,375 & 0,568 & 0,529 \\
\hline ES 1 & 0,475 & 0,483 & 0,418 & 0,849 & 0,452 & 0,419 & 0,498 & 0,336 & 0,499 & 0,368 \\
\hline ES2 & 0,392 & 0,501 & 0,400 & 0,836 & 0,432 & 0,460 & 0,450 & 0,295 & 0,495 & 0,434 \\
\hline ES3 & 0,571 & 0,547 & 0,439 & 0,797 & 0,404 & 0,455 & 0,553 & 0,369 & 0,531 & 0,503 \\
\hline ITI & 0,381 & 0,526 & 0,463 & 0,426 & 0,899 & 0,737 & 0,591 & 0,327 & 0,448 & 0,302 \\
\hline IT2 & 0,459 & 0,611 & 0,537 & 0,496 & 0,964 & 0,830 & 0,653 & 0,371 & 0,539 & 0,441 \\
\hline IT3 & 0,480 & 0,658 & 0,570 & 0,535 & 0,960 & 0,850 & 0,712 & 0,389 & 0,576 & 0,458 \\
\hline REC 1 & 0,456 & 0,635 & 0,500 & 0,509 & 0,866 & 0,946 & 0,672 & 0,376 & 0,585 & 0,461 \\
\hline REC2 & 0,449 & 0,640 & 0,496 & 0,508 & 0,756 & 0,945 & 0,662 & 0,441 & 0,527 & 0,487 \\
\hline S1 & 0,336 & 0,367 & 0,252 & 0,265 & 0,232 & 0,283 & 0,317 & 0,827 & 0,178 & 0,179 \\
\hline S2 & 0,290 & 0,348 & 0,291 & 0,249 & 0,186 & 0,232 & 0,290 & 0,790 & 0,122 & 0,236 \\
\hline S3 & 0,456 & 0,606 & 0,452 & 0,434 & 0,452 & 0,478 & 0,533 & 0,867 & 0,368 & 0,367 \\
\hline SATI & 0,624 & 0,750 & 0,623 & 0,610 & 0,695 & 0,706 & 1,000 & 0,491 & 0,682 & 0,519 \\
\hline UT1 & 0,483 & 0,505 & 0,463 & 0,530 & 0,518 & 0,541 & 0,627 & 0,219 & 0,876 & 0,478 \\
\hline UT2 & 0,538 & 0,538 & 0,487 & 0,518 & 0,456 & 0,467 & 0,573 & 0,264 & 0,866 & 0,420 \\
\hline UT3 & 0,534 & 0,574 & 0,504 & 0,561 & 0,474 & 0,522 & 0,575 & 0,309 & 0,864 & 0,459 \\
\hline $\mathrm{VHl}$ & 0,236 & 0,354 & 0,253 & 0,404 & 0,234 & 0,324 & 0,294 & 0,231 & 0,340 & 0,708 \\
\hline $\mathrm{VH} 2$ & 0,369 & 0,404 & 0,342 & 0,481 & 0,293 & 0,353 & 0,367 & 0,247 & 0,430 & 0,705 \\
\hline VH3 & 0,359 & 0,434 & 0,518 & 0,363 & 0,358 & 0,397 & 0,435 & 0,269 & 0,411 & 0,853 \\
\hline $\mathrm{VH} 4$ & 0,395 & 0,475 & 0,616 & 0,429 & 0,422 & 0,471 & 0,490 & 0,298 & 0,443 & 0,848 \\
\hline
\end{tabular}

Fonte: Saída do Software SmartPLS

Fornell-Larcker estabelece que a variável latente (construto) deve compartilhar mais variância com seus indicadores do que com as outras variáveis latentes (outros construtos do modelo). Assim, a AVE de cada variável latente deve ser maior do que o quadrado da maior correlação com outra variável latente (Henseler et al., 2009). 
Conforme a Tabela 5 todos os valores de Fornell-Larcker são adequados.

Tabela 5 - Fornell-Larcker

\begin{tabular}{|c|c|c|c|c|c|c|c|c|c|c|}
\hline \multicolumn{11}{|c|}{ Fornell-Larcker } \\
\hline & Conf. & Conven. & Design & $\begin{array}{l}\text { Exp. c/ } \\
\text { Serviços }\end{array}$ & $\begin{array}{l}\text { Int. de } \\
\text { Reserva }\end{array}$ & Recomen. & Satisf. & Segur. & $\begin{array}{l}\text { Util. do } \\
\text { Site }\end{array}$ & $\begin{array}{l}\text { Valor } \\
\text { Hed. }\end{array}$ \\
\hline Confiança & 0,844 & & & & & & & & & \\
\hline Conven. & 0,570 & 0,766 & & & & & & & & \\
\hline Design & 0,494 & 0,709 & 0,914 & & & & & & & \\
\hline $\begin{array}{l}\text { Exp. c/ } \\
\text { Serviço }\end{array}$ & 0,588 & 0,620 & 0,508 & 0,828 & & & & & & \\
\hline $\begin{array}{l}\text { Int. de } \\
\text { Reserva }\end{array}$ & 0,470 & 0,639 & 0,559 & 0,518 & 0,942 & & & & & \\
\hline Recomen. & 0,479 & 0,674 & 0,527 & 0,538 & 0,858 & 0,945 & & & & \\
\hline Satisfação & 0,624 & 0,750 & 0,623 & 0,610 & 0,695 & 0,706 & 1,000 & & & \\
\hline Segurança & 0,455 & 0,567 & 0,425 & 0,407 & 0,386 & 0,432 & 0,491 & 0,829 & & \\
\hline Util. do Site & 0,595 & 0,619 & 0,557 & 0,617 & 0,557 & 0,588 & 0,682 & 0,302 & 0,869 & \\
\hline $\begin{array}{l}\text { Valor } \\
\text { Hedôn. }\end{array}$ & 0,442 & 0,538 & 0,580 & 0,530 & 0,430 & 0,501 & 0,519 & 0,336 & 0,522 & 0,782 \\
\hline
\end{tabular}

Fonte: Saída do Software SmartPLS

O último critério usado para a análise da validade discriminante foi o Heterotrait-Monotrait Ratio (HTMT) que é semelhante aos das cargas cruzadas e Fornell-Larcker, visando determinar se o construto é único (Henseler et al., 2015). Os valores de HTMT entre as relações dos construtos devem ser menores que 0,9, para resultados mais conservadores o indicado é que o valor de HTMT seja inferior a 0,85 . De acordo com a tabela 6, todos os valores de HTMT são bons, exceto Recomendação -> Intenção de Reserva cujo valor é de 0,942. 
ISTA CIENTIFICA DO CURSO DE POS.GRADUACAOS STRICTO SENSU
TURISMO E HOTELARIA DA UNIVERSIDADE DO VALE DO ITAJAI

VISÃO E AÇÃO

Tabela 6 - Heterotrait-Monotrait Ratio (HTMT)

\begin{tabular}{|c|c|c|c|c|c|c|c|c|c|c|}
\hline \multicolumn{11}{|c|}{ HTMT $<0,90$} \\
\hline & Conf. & Conven. & Design & $\begin{array}{l}\text { Exp. c/ } \\
\text { Serviços }\end{array}$ & $\begin{array}{l}\text { Int. de } \\
\text { Reserva }\end{array}$ & Recomen. & Satisf. & Segur. & $\begin{array}{l}\text { Util. } \\
\text { do } \\
\text { Site }\end{array}$ & $\begin{array}{l}\text { Valor } \\
\text { Hed. }\end{array}$ \\
\hline Confi. & & & & & & & & & & \\
\hline Conven. & 0,700 & & & & & & & & & \\
\hline Design & 0,578 & 0,809 & & & & & & & & \\
\hline $\begin{array}{l}\text { Exp. c/ } \\
\text { Serviços }\end{array}$ & 0,737 & 0,773 & 0,603 & & & & & & & \\
\hline $\begin{array}{l}\text { Int. de } \\
\text { Reserva }\end{array}$ & 0,540 & 0,714 & 0,602 & 0,607 & & & & & & \\
\hline Recom. & 0,570 & 0,785 & 0,588 & 0,651 & 0,942 & & & & & \\
\hline Satisf. & 0,698 & 0,817 & 0,652 & 0,688 & 0,716 & 0,752 & & & & \\
\hline Segur. & 0,543 & 0,649 & 0,472 & 0,480 & 0,402 & 0,475 & 0,511 & & & \\
\hline Util. do Site & 0,729 & 0,742 & 0,639 & 0,764 & 0,624 & 0,683 & 0,744 & 0,330 & & \\
\hline $\begin{array}{l}\text { Valor } \\
\text { Hedônico }\end{array}$ & 0,547 & 0,654 & 0,657 & 0,681 & 0,480 & 0,592 & 0,570 & 0,390 & 0,637 & \\
\hline
\end{tabular}

Fonte: Saída do Software SmartPLS

\section{MODELO ESTRUTURAL}

Para a análise do teste do modelo estrutural proposto pelo estudo, foram usados os coeficientes de caminho, os coeficientes de determinação e o SRMR. No modelo foi testado o bootstrapping no software SmartPLS com uma subamostra de 1500, a análise do modelo estrutural avalia a capacidade de previsão do modelo e as relações entre os construtos. 
Figura 2 - Modelo de Estrutural

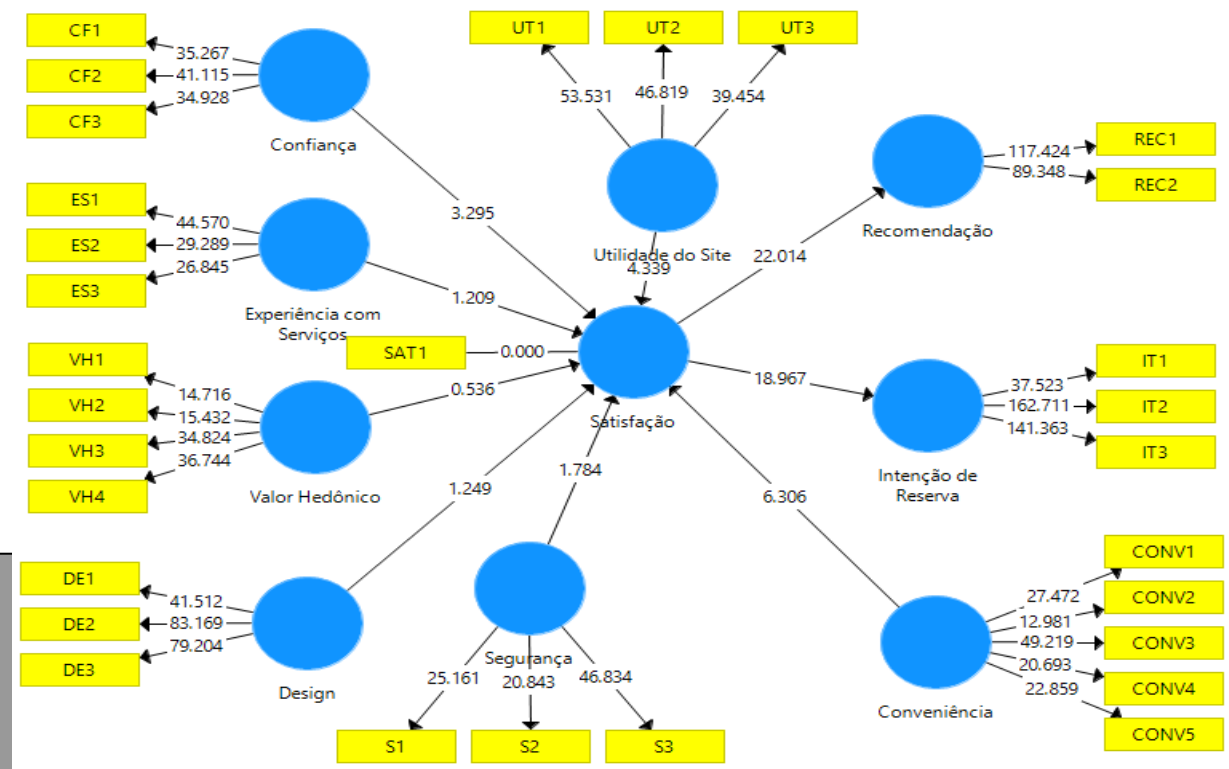

Fonte: Saída do Software SmartPLS

Os coeficientes de caminho representam as relações hipotéticas entre os construtos. Para identificar se um coeficiente é significativo, utilizou-se o teste T, cujos valores devem ser superiores ao valor crítico, que é 2,57 para o nível de significância de 1\%, 1,96 para o nível de significância de 5\% e 1,57 para o nível de significância de 10\% (Hair et al., 2014).

A Tabela 7 apresenta os resultados dos coeficientes de caminho e como pode ser visto, três hipóteses não são significantes: Design -> Satisfação, Experiência com Serviços -> Satisfação e Valor Hedônico -> Satisfação. 
Tabela 7 - Coeficientes de Caminho

\begin{tabular}{|c|c|c|c|c|}
\hline Hipóteses & $\begin{array}{l}\text { Estatística } \\
\text { T }\end{array}$ & P Valor & Significância & Resultado \\
\hline Confiança -> Satisfação & 3,295 & 0,001 & $1 \%$ & Suportado \\
\hline $\begin{array}{l}\text { Lonveniencia -> } \\
\text { Satisfacão }\end{array}$ & 6,306 & 0,000 & $1 \%$ & Suportado \\
\hline Design -> Satisfação & 1,249 & 0,212 & Não & Não \\
\hline Exp.com Serviços -> & & & $\begin{array}{l}\text { significante } \\
\text { Năo }\end{array}$ & $\begin{array}{l}\text { Supportado } \\
\text { Năo }\end{array}$ \\
\hline $\begin{array}{l}\text { Satisfação } \\
\text { Satisfaçăo -> Intence }\end{array}$ & 1,209 & 0,221 & significante & Suportado \\
\hline $\begin{array}{l}\text { Reserva } \\
\text { Reşána }\end{array}$ & 18,967 & 0,000 & $1 \%$ & Suportado \\
\hline $\begin{array}{l}\text { Satistaçao -> } \\
\text { Recomendacão }\end{array}$ & 22,014 & 0,000 & $1 \%$ & Suportado \\
\hline Segurança -> Satisfação & 1,784 & 0,075 & $10 \%$ & \\
\hline $\begin{array}{l}\text { Satisfação } \\
\text { Salliade -> }\end{array}$ & 4,339 & 0,000 & $1 \%$ & Suportado \\
\hline $\begin{array}{l}\text { Valor Hedônico -> } \\
\text { Satisfação }\end{array}$ & 0,536 & 0,592 & $\begin{array}{l}\text { Não } \\
\text { significante }\end{array}$ & $\begin{array}{l}\text { Não } \\
\text { Suportado }\end{array}$ \\
\hline
\end{tabular}

Fonte: Saída do Software SmartPLS

O coeficiente de determinação é a medida do poder de previsão do modelo. Os coeficientes de determinação devem ser avaliados pelos parâmetros de valores de 0,19,0,33 e 0,67, sendo respectivamente, fracos, moderados e substanciais (Henseler et al., 2009; Hair et al., 2014).

Tabela 8 - Coeficiente de Determinação

\begin{tabular}{|lll|}
\hline Construto & $\mathbf{R}^{\mathbf{2}}$ & $\begin{array}{l}\mathbf{R}^{\mathbf{2}} \\
\text { Ajustado }\end{array}$ \\
\hline $\begin{array}{l}\text { Intenção de } \\
\text { Reserva }\end{array}$ & 0,483 & 0,481 \\
Recomendação & 0,498 & 0,496 \\
Satisfação & 0,671 & 0,664 \\
\hline
\end{tabular}

Fonte: Saída do Software SmartPLS

O Standardized Root Mean Square Residual (SRMR), ou raiz quadrada média residual padronizada é definida como a diferença entre a correlação observada e a correlação prevista. De acordo com Hu e Bentler (1998) um valor até 0,10 é considerado bom. O SRMR observado foi 0,067 e o SRMR estimado foi de 0,085 , assim, ambos são adequados. 


\section{CONCLUSÃO}

O objetivo deste trabalho foi analisar os motivos que levavam consumidores de sites de reserva de hotéis a recomendá-los para outras pessoas. Para isso, a pesquisa se dividiu em uma etapa qualitativa e outra quantitativa.

Na etapa qualitativa, os respondentes indicaram que usam os sites para ter mais praticidade e comodidade nas suas viagens. No entanto, essa utilização estava condicionada pela confiança que eles atribuíam a esses sites. Tal confiança era formada pela avaliação de dois atributos: segurança na forma de pagamento e credibilidade das avaliações de outros usuários. Esses resultados forneceram insights importantes para esta pesquisa. Em primeiro lugar, indicam que os consumidores de serviços turísticos querem ter o controle do planejamento e da execução das suas viagens, incluindo a flexibilidade de mudar sua programação sem esbarrar em restrições comuns no passado. Isso fica claro quando eles responderam que prezam pela praticidade e pela comodidade oferecidas pelos sites de reservas. No passado, essa demanda era prioritariamente mediada pelas agências de turismo, implicando uma maior dependência dos consumidores em relação a esses prestadores de serviço. Percebe-se, portanto, uma importante mudança na relação do consumo de serviços turísticos.

O segundo insight derivado dos resultados da etapa qualitativa é que os consumidores desejam usar serviços de reserva online, mas repudiam um serviço qualquer. Para esses consumidores, sua viagem é importante o suficiente para merecer o cuidado com o tipo de serviço online que mediará o seu planejamento e a sua execução. Nesse sentido, os consumidores basicamente pautam sua decisão de usar determinado site de acordo com dois atributos: confiabilidade do pagamento e credibilidade das avaliações de outros usuários.

Esses dois atributos indicam a importância da viagem para os consumidores. Ao enfatizar suas preocupações com a segurança nos pagamentos, eles mostram que desejam seus recursos financeiros utilizados somente na viagem, sem ter que lidar com problemas que os façam perder tais recursos. Por outro lado, a atenção dada às avaliações de outros usuários ajuda esses consumidores a diminuir a incerteza sobre a competência de um site para efetivamente prover um serviço satisfatório.

Os resultados da etapa quantitativa são coerentes com essas observações. A confiança e, principalmente, a conveniência afetam positivamente a satisfação dos consumidores com os sites de reserva. Mais uma vez, detecta-se que os consumidores desejam ter a comodidade de controlar todas as etapas da sua viagem, ao mesmo tempo em que usam um serviço online de credibilidade atestada por outros usuários.

O modelo quantitativo também mostrou que a satisfação dos consumidores se relaciona positivamente com a sua intenção em efetivar a 
reserva e com a sua disposição em recomendar o site para outras pessoas. Fecha-se, portanto, um círculo virtuoso: serviços online que oferecem mais conveniência e que atraem mais a confiança conseguem ter consumidores mais satisfeitos. Por sua vez, estes têm maior propensão a efetivar a reserva e a recomendar o site para outras pessoas.

Os resultados obtidos as etapas qualitativa e quantitativa apontam para implicações gerenciais importantes. A primeira é que os serviços de reservas online precisam estar atentos para a experiência de navegação dos consumidores, cada vez mais exigentes com a comodidade. A segunda é que tal comodidade tem que ser acompanhada da confiança construída a partir da segurança oferecida pelo serviço na forma de pagamento e na credibilidade do site junto à comunidade de usuários.

Em decorrência disso, a terceira implicação é que os sites precisam considerar que atuam em um segmento de mercado altamente competitivo. Dessa forma, oferecer um serviço que não resulte em uma boa experiência de consumo implicará um público com menor tendência a efetivar a reserva e a recomendar o site para outras pessoas.

Apesar desses resultados, esta pesquisa tem limitações. A mais significativa é a impossibilidade de se generalizar os resultados, uma vez que a amostra foi não probabilística. Essa generalização é importante para estender os resultados do modelo a uma população e, por essa razão, pesquisas futuras devem contemplar esse aspecto. Ademais, isso ajudaria a revisar os testes realizados, verificando se, em outra amostra, as hipóteses seriam sustentadas.

Uma segunda limitação foi usar um grupo único na amostra, não se estimando modelos para grupos formados por diferentes critérios, como sexo, por exemplo. Dessa forma, não há como saber se a não confirmação de parte das hipóteses se deveu a eventuais diferenças entre esses grupos. Portanto, sugere-se que pesquisas futuras estimem modelos distintos para cada grupo de respondentes, comparando os resultados.

\section{REFERÊNCIAS}

Barrozo, M. M. A. (2013) Impacto dos comentários em sites de viagem na intenção de reserva de hotel online. (Monografia de Graduação) Departamento de Administração, Universidade de Brasília.

Bhattacherjee, A. (2001) Understanding Information Systems Continuance: An Expectation-Confirmation Model. MIS Quarterly, 25(3), 351-370.

Blackwell, R. D., Miniard, P. W., \& Engel, J. F. (2005). Comportamento do consumidor. 9 ed. São Paulo: Pioneira Thomson Learning.

Boshoff, C. (2007) A psychometric assessment of E-S-QUAL: a scale to measure electronic service quality. Journal of Electronic Commerce Research, Stellenbosch, 8 (1).

Camargo, L. O. D. L., Cavenaghi, A. J., Pereira, D. C., \& Wada, E. K. (2018). Os fãs do SESC em São Paulo: um estudo sobre hospitalidade e acolhimento. Revista Brasileira de Pesquisa em Turismo, 12(2), 46-64. 
Carrilho, B., \& Vellani, M. (2011) A importância da internet para o setor hoteleiro. FAESO - Revista de Humanidades e Ciências Sociais Aplicadas.

Cho, E., \& Kim, Y .K. (2012) The effects of website designs, self-congruity, and flow on behavioral intention. International Journal of Design, 6(2), 31-39.

Chung, N., Lee, H., Lee, S. J., \& Koo, C. (2015) The influence of tourism website on tourists' behavior to determine destination selection: A case of study of creative economy in Korea. Technological Forecasting \& Social Change, 96, 130-143.

Coelho, L. S., Oliveira, R. C., \& Alméri, T. M. (2013) O crescimento do e-commerce e os problemas que o acompanham: a identificação da oportunidade de melhoria em uma rede de comércio eletrônico na visão do cliente. Revista de Administração do UNISAL, 3(3), 63-85.

Coelho, M. F. (2013) Atratividade turística, imagem, reputação e recomendação online: um modelo integrativo das percepções de turistas de Ouro Preto. Dissertação (Mestrado em Administração) - Faculdade de Ciências Econômicas, Universidade Federal de Minas Gerais, Minas Gerais.

Cummins, S., Peltier, J. W., Schibrowsky, J. A., \& Nill, A. (2014) Consumer behavior in the online context. Journal of Research in Interactive Marketing, 8, $169-202$.

Dedeke, A. N. (2016). Travel web-site design: Information task-fit, service quality and purchase intention. Tourism Management, 54, 541-554.

Delone, W., \& Mclean, E. (1992) Information Systems Success: The Quest for the Dependent Variable. Information Systems Research, 3(1).

Delone, W., \& Mclean, E. (2003) The DeLone and McLean Model of Information Systems Success: A Ten-Year Update. Journal of Management Information Systems, 19.

Eltz, B. S., \& Bridi, G. (2016) E-commerce no turismo e na hotelaria. A importância das ferramentas virtuais no processo de consulta e aquisição de viagens. FOLIO Revista Científica Digital - Jornalismo, Publicidade e Turismo, 65-82.

Faizan, A. (2016) Hotel website quality, perceived flow, customer satisfaction and purchase intention. Journal of Hospitality and Tourism Technology. 7, 213-288.

Fang, Y., Qureshi, I., Sun, H., Mccole, P., Ramsey, E., \& Lim, K. Trust, Satisfaction, and Online Repurchase Intention: The Moderating Role of Perceived Effectiveness of E-Commerce Institutional Mechanisms. Management Information Systems Quarterly, 38(2), 2014.

Fratu, D. (2011) Factors of influence and changes in the tourism consumer behavior. Bulletin of the Transilvania University of Brasov, 4(1), 119-126.

Frederico, E., Cantafaro, R. T., Aydar, F. R., \& Shinzaki, A. P. M. (2014) Valor, satisfação e recomendação espontânea para uma marca varejista. Revista Brasileira de Marketing, 13(6),107-123.

Geraldo, G. C., \& Mainardes, E. W. (2017). Estudo sobre os fatores que afetam a intenção de compras online. REGE-Revista de Gestão, 24(2), 181-194.

Hair, J., Anderson, R. E., Tathem, R. L., \& Black, W. C. (2005) Análise Multivariada de Dados. Porto Alegre: Bookman. 
Hair, J., Hult, G. T. M., Ringle, C. M., \& Sarstedt, M. (2014) A Primer on Partial Least Squares Structural Equation Modeling (PLS-SEM). Los Angeles: Sage Publications.

Henseler, J., Ringle, C. M., \& Sinkovics, R. R. (2009) The use of partial least squares path modeling in international marketing. Advances in International Marketing (AIM), 20, 277-320.

Henseler, J., Ringle, C. M., \& Sarstedt, M. (2015) A new criterion for assessing discriminant validity in variance-based structural equation modeling. Journal of the Academy Marketing Science, 43, 115-135.

Hu, L. T., \& Bentler, P. M. (1998) Fit indices in covariance structure modeling: sensitivity to underparameterized model misspecification. Psychological Methods, 3(4), 424-453.

Hwang, Y., \& Jeong, J. (2016) Electronic commerce and online consumer behaviour research: A literature review. Information Development, 32, 377-388.

Kovacs, M. H., \& Farias, S. A. (2004) Dimensões de riscos percebidos nas compras pela internet. Revista de Administração de Empresas, 3(2).

Ladhari, R., \& Michaud, M. (2015) EWOM Effects on Hotel Booking Intentions, Attitudes, Trust, and Website Perceptions. International Journal of Hospitality Management, 46.

Lee, G. G., \& Lin, H. F. (2015) Customer perceptions of e-service quality in online shopping. International Journal of Retail \& Distribution Management, 33(2), 161 - 176.

Leitinho, R. R., \& Farias, J. S. (2018). A motivação hedônica no consumo de bens virtuais cosméticos em jogos online. Revista Brasileira de Marketing, 17(1), 65-79.

Litvin, S. W., Goldsmith, R. E., \& Pan, B. (2008) Electronic word-of-mouth in hospitality and tourism management. Tourism Management, 29, 458-468.

Mas-Colell, A., Whinston, M., Green, J. (2010). Microeconomic theory. Oxford: Oxford University. Cap. 1.

Mirabent, J. B., Machuca, M. M., \& Marimon, F. (2015) Antecedents of online purchasing behaviour in the tourism sector. Industrial Management \& Data Systems, 116, 87-102.

Molina, M. A. R., Jamilena, D. M. F., \& García, J. A. C. (2015) The contribution of website design to the generation of tourist destination image: The moderating effect of involvement. Tourism Management, 47, 303-317.

Mowen, J. C., \& Minor, M. S. (2003) Comportamento do consumidor. São Paulo: Pearson Prentice Hall.

Niemczyk, A. (2014) The Application of Path Modelling in the Analysis of Consumer Behaviour in the Cultural Tourism Market. Economics \& Sociology, 7(1), 204-216.

Nunnally, J., Bernstein, I. (1994) Psychometric theory. 3 ed. New York: McGraw-Hill.

Oliveira, M. C. (2013) Efeitos da recomendação online no comportamento do consumidor: um estudo envolvendo confiança, satisfação, recomendação e intenção de compra. 2013. (Dissertação de Mestrado). Faculdade de Economia, Administração e Contabilidade, Universidade de São Paulo, São Paulo. 
Oneto, A. A. D., Ferreira, J. B., Giovannini, C. J., \& da Silva, J. F. (2015). Confiança e Satisfação na Compra de turismo online. Revista Brasileira de Pesquisa em Turismo, 9(2), 221-239.

Parasuraman, A., Zeithaml, V. A., \& Malhotra, A. (2005) E-S-QUAL: A Multiple-ltem Scale for Assessing Electronic Service Quality. Journal of Service Research, [S.I.].

Peighambari, K., Sattari, S., Kordestani, A., \& Oghazi, P. (2016) Consumer Behavior Research: A Synthesis of the Recent Literature. SAGE Open, 1 - 9.

Peng, L., \& Lai, L. (2014) A service innovation evaluation framework for tourism e-commerce in China based on BP neural network. Electron Markets, 37-46.

Silva, M. M., \& Filho, L. M. (2014) Intenção de uso de comentários de viagem online na escolha de um meio de hospedagem: Fatores influenciadores. Revista Brasileira de Pesquisa em Turismo. São Paulo, 419-434.

Shoemaker, S., \& Lewis, R. C. (1999) Customer loyalty: the future of hospitality marketing. International Journal of Hospitality Management, 18(4), 345-370.

Veludo-de-Oliveira, T. M., \& Huertas, M. K. Z. (2018). Satisfação, Confiança e Familiaridade no Varejo Online e o Papel Moderador da Experiência. Revista Brasileira de Marketing, 17(3), 415-428.

Villanueva, J., Yoo, S., \& Hanssens, D. M. (2008) The Impact of Marketing-Induced Versus Word-of-Mouth Customer Acquisition on Customer Equity Growth. Journal of Marketing Research (JMR), 45(1), 48-59.

Vilar, M. A. S. (2013) Modelo de aceitação da Tecnologia adaptado às compras online. (Dissertação de Mestrado). Universidade Fernando Pessoa.

Wu, H. C., \& Cheng, C. C. (2018). What drives supportive intentions towards a dark tourism site?. International Journal of Tourism Research, 20(4), 458-474.

Yenn Wei, A. T., Hiribae, C. M., Kuen, D. Y. M., Yi, L.C., \& Yee Ling, P. (2014) Electronic word of mouth's (EWOM'S) influence on booking intention: A study of hotels in Kuala Lumpur. Faculty of Business and Finance. Department of Commerce and Accountancy. University Tunku Abdul Rahman.

Contribuição de cada autor na construção do artigo:

Marlusa de Sevilha Gosling: Concepção do projeto total da pesquisa, orientação de todas as etapas.

Felipe Willian Toledo Fortes: Referencial teórico e coleta de dados.

Humberto Elias Garcia Lopes: Referencial teórico e coleta de dados.

lury Teixeira de Sevilha Gosling: Análise de resultados.

Kelly Cristine Oliveira Meira: 